\title{
Lessons from Two Anthropogenic Environmental Disasters in Contemporary Japanese History
}

\author{
Guangwei Huang* \\ Sophia University, Japan
}

ISSN: 2576-8816

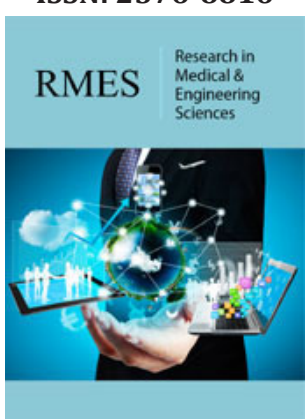

*Corresponding author: Guangwei Huang, Sophia University, Japan

Submission: 温 October 24, 2019

Published: 制 November 20, 2019

Volume 8 - Issue 3

How to cite this article: Guangwei Huang. Lessons from Two Anthropogenic Environmental Disasters in Contemporary Japanese History. Res Med Eng Sci. 8(3). RMES.000687.2019.

DOI: 10.31031/RMES.2019.08.000687

Copyright@ Guangwei Huang, This article is distributed under the terms of the Creative Commons Attribution 4.0 International License, which permits unrestricted use and redistribution provided that the original author and source are credited.

\section{Introduction}

An environmental disaster is a catastrophic event caused by human activity that results in serious effects on ecosystems, agriculture, the economy and human health. In most cases environmental disasters are caused by human error, accident, lack of knowledge and foresight. To distinguish them from naturally occurring disasters, environmental disaster can be termed anthropogenic or man-made environmental disaster.

Mining and industrial pollution have been the cause of so many environmental disasters. One example of the worst environmental disasters, the Bhopal disaster was a gas leak incident on the night of 2-3 December 1984 at the Union Carbide India Limited (UCIL) pesticide plant in Bhopal, Madhya Pradesh, India [1,2]. Over 500,000 people were exposed to methyl isocyanate (MIC) gas, which is highly toxic. The estimation of death toll varied from 3,787 to 8000 . Another example is Ok Tedi mine [3]. It discharged about two billion tons of untreated mining waste into the Ok Tedi river and the Fly river in the Western Province of Papua New Guinea between 1984 and 2013. The lives of 50,000 people had been disrupted. Two representative environmental disasters in modern Japanese history may be chosen as (1) Ashio Copper Mine pollution; (2) Minamata disease. Although they have been studied extensively [4], some lessons from the two cases are still missing in the literature. The objective of this paper is to highlight some view angles that have been very much neglected so far.

\section{Ashio Copper Mine Pollution}

The Ashio Copper Mine, located in the upstream of the Watarase River Basin (WRB), had produced 1,500 tons annually in the 1600s, which was the maximum possible output in Japan that time. In 1884, the production stood at 2,286 tons per year accounting for 26 per cent of Japan's copper production. The production system of the Ashio Copper Mine brought about serious mining-induced environmental destruction. The sulfur dioxide generated from the refining process caused all the trees surrounding the mine to die by the end of 1884 [5]. The destruction of forest increased the frequency of surface runoff in the watershed and flood waters transported large amounts of toxic heavy metals released from the mine to farmlands downstream, damaging the agriculture and farmer's livelihood in the watershed.

In 1903 the national government of Japan decided to construct a flood retarding basin to prevent the heavy metals from moving further downstream to reach the capital city. Therefore, this basin can also be characterized as pollutants catchment basin. The location of the basin was proposed in an area close to the river mouth of the Watarase river before joining the Tone river, with the Yanaka village ultimately identified as the appropriate site for constructing this basin [6,7]. Today, the WRB is characterized as having a 3,300ha reed bed, home to 1,000 species of plants, 1,700 species of insects, and 252 species of birds. On July 3, 2012 the WRB was registered under the Ramsar Convention as a wetland of international importance.

However, a recent survey in a number of locations within WRB showed that concentrations of heavy metals in topsoil were in the following ranges: $\mathrm{Pb}: 37-167 \mathrm{mg} / \mathrm{kg}$; $\mathrm{Cd}: 0.12-13.3 \mathrm{mg} /$ $\mathrm{kg} ; \mathrm{Cu}: 21.3-150.2 \mathrm{mg} / \mathrm{kg}$, and $\mathrm{Cr} 6+: 2.1-32.6 \mathrm{mg} / \mathrm{kg}$ [8]. Considering the spatial scale and the thickness of the wetland soil, there could be much high heavy metal residues in the WRB. The study also revealed that the registration of the wetland as a Ramsar site has guided the general public to view the wetland in certain direction that might mask the dark history of the 
WRB and affect the comprehension of the history and the current environmental condition of the wetland by the general public.

\section{Minamata Disease}

It is a disease of the central nervous system and was first discovered in the Minamata city in Kumamoto prefecture, Japan, in 1956. It was caused by the consumption of fish and shellfish contaminated with methyl mercury compounds, which was released into the environment by wastewater from the Chisso Corporation's chemical factory and then accumulated in the marine life. The symptoms of Minamata disease include the loss of sensation in the hands and feet, difficulty in coordinating movement of hands and feet, narrowing of the field of vision, hearing impairment, speech impediments and other disorders [9].

After the existence of the disease was officially recognized on May l, 1956, the investigation into the cause took a long time. On July 22, 1959, the Kumamoto University Study Group led by Professor Tadao Takeuchi and Assistant Professor Haruhiko Tokuomi, based on the pathological and clinical research of, made a formal announcement that Minamata disease is caused by eating mercury-contaminated fish and shellfish [10]. On August 5, 1959, at a Special Minamata Disease Committee meeting of the Kumamoto Prefectural Assembly, Chisso reported that "The organic mercury theory of Kumamoto University is a speculation without actual proof, and it is irrational in view of chemistry common sense" [11].

As research proceeded on organic mercury, the Kumamoto University Study Group made a formal announcement on February 20 , 1963, stating that the cause of intoxication is a methyl mercury compound found in the shellfish, as well as in the sludge of the Chisso Minamata factory. Then, the national government announced its official opinion on Minamata disease on September 26,1968 . They concluded that "Minamata disease is a disease of the central nervous system caused by a methyl mercury compound". The verdict-making took more than a decade. It should also be mentioned that on July 24, 1957, a Committee of Kumamoto Prefecture on Measures against the Minamata Unknown Disease decided to announce its plan under Article 4 of the Food Sanitation Act, to prohibit the capturing of fish and shellfish for retail purposes from Minamata Bay and consulted with the Ministry of Health and Welfare of Japan on the possible implementation of the Food Sanitation Act regarding fish and shellfish taken from Minamata on August 16, 1957. On September 11, the Ministry of Health and Welfare replied, "As there is no clear evidence that all fish and shellfish of a specific area of Minamata Bay are contaminated, the Food Sanitation Act is not applicable to fish and shellfish caught in Minamata Bay".

After the verdict, another 10 years elapsed without any cleanup campaign. On October 1, 1977, the Minamata Bay Pollution Prevention Project was initiated to dispose of sedimentary sludge containing over 25ppm of mercury in Minamata Bay. The approach is to transform a large portion of the sea into an enclosed land and move all excavated sediment sludge into it and then cover the land with clean soil [12] as shown in Figure $1 \& 2$.

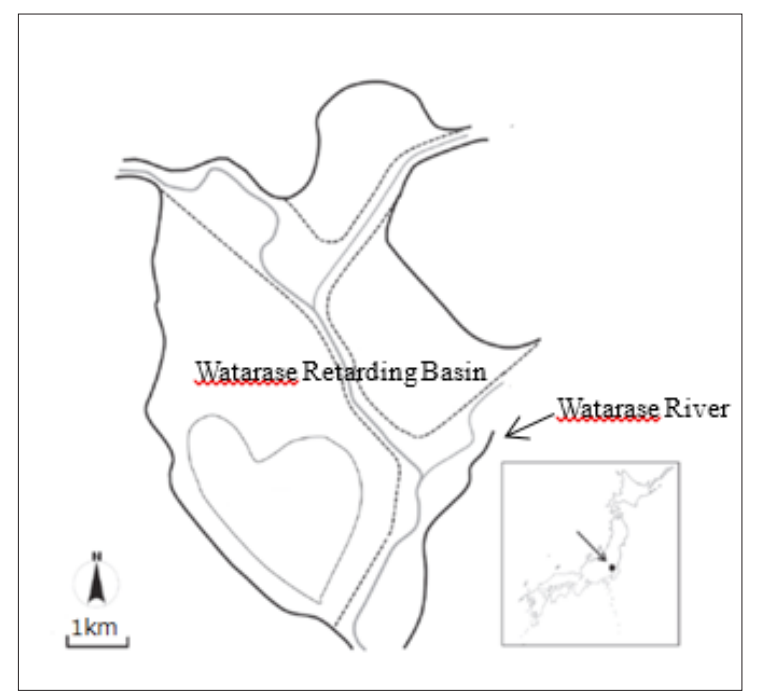

Figure 1: Watarase Retarding Basin.

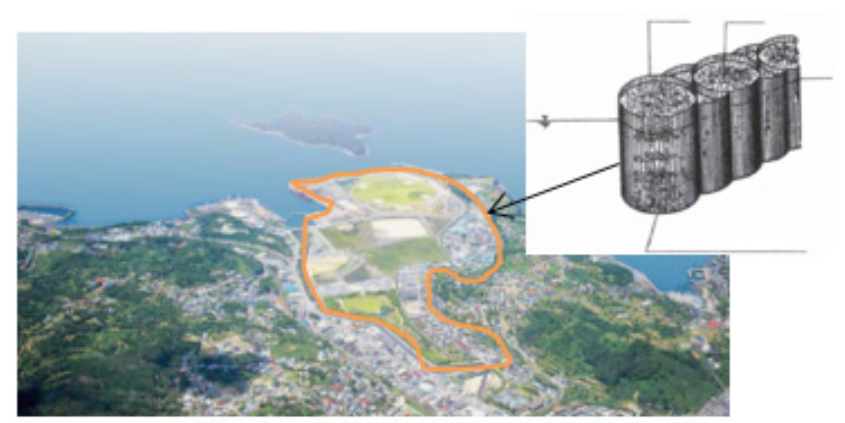

Figure 2: Land reclamation in Minamata Bay.

\section{Discussion and Conclusion}

In both cases, the company responded in a wrong way at the initial stage and the central government did not act timely. At the end, the countermeasures taken by the national government in both cases were the confinement of toxic materials in a planned area. In the case of Ashio Mine, the Watarase Retarding Basin was used for the purpose of confining heavy metals and in the case of Minamata, the land reclamation in Minamata Bay created a burying area for the mercury. However, these sites are a potential concern of risk in the long term since in-situ detoxification measures have been given little attention and Japan is an earthquake-prone country, which may cause the re-surface of toxic materials. Furthermore, the danger is being forgotten by the general public so quickly.

In the case of Ashio Mine, the heavy metals damaged rice production and the no or little yield consequence indeed prevented the consumption of contaminated food. In the Minamata case, fishes in Minamata Bay were contaminated but not killed. As a result, mercury entered human bodies due to the consumption of contaminated fish and shellfish. This is the reason why the Minamata case resulted in more victims than the Ashio Mine case. As a matter of fact, the fish catch from the bay was significantly decreased in the second half of the 1950s, which could have 
been recognized as evidence of contamination. Nevertheless, the company did not make efforts to treat its effluent sufficiently. Instead, it changed the location of wastewater discharge from the Minamata River mouth to an open sea site in 1958, which further spread out the mercury. Such a dilution measure kept fish and shellfish in the bay alive but with the accumulation of mercury in their bodies. Meanwhile, Kumamoto Prefectural government did not impose any regulation to stop the consumption of contaminated fish and shellfish harvested from the bay. Among the victims of the disease, the highest concentration of mercury in the brain was found to be $10 \mathrm{ppm}$ [10]. Usually, a level of $0.05 \mathrm{ppm}$ in the brain can be fatal. Besides, the highest level of mercury concentration in hairs of victims was found to be 1855ppm [11]. Since Japanese consume a lot of seafood, the concentration of mercury in hairs of ordinary Japanese range from 10 to $20 \mathrm{ppm}$. For people with this level of mercury in hair, no symptom of Minamata disease was ever reported. According to IPCS Environmental Health Criteria No.101 Methylmercury, the levels at which neurological symptoms would appear in the most sensitive adults are shown in Table 1.

Table 1:

\begin{tabular}{|c|c|}
\hline Average Daily Intake & $\mathbf{3 - 7} \boldsymbol{\mu g} / \mathrm{kg}$ \\
\hline Body burden & $15-35 \mathrm{mg}(50 \mathrm{~kg}$ weight $)$ \\
\hline Total mercury concentration in blood & $20-50 \mu \mathrm{g} / 100 \mathrm{ml}$ \\
\hline Total mercury concentration in hair & $50-125 \mu \mathrm{g} / \mathrm{g}$ \\
\hline
\end{tabular}

A concluding remark is the effect of environmentally unsound business on people's livelihood can far outweigh the benefits the business may generate and the damage on both environment and people's health can be long lasting. To avoid such tragedy, the role of government in monitoring and regulating is vital and must be ensured to function.

\section{References}

1. Eckerman, Ingrid (2005) The Bhopal saga-causes and consequences of the world's largest industrial disaster. Universities Press, India.

2. Varma, Roli, Daya V (2005) The bhopal disaster of 1984. Bulletin of science, technology \& society 25(1): 37-45.

3. Hettler, Irion, Lehmann (1997) Environmental impact of mining waste disposal on a tropical lowland river system: a case study on the Ok Tedi Mine, Papua New Guinea. Mineralium Deposita 32(3): 280-291.

4. Jun Ui (1992) Industrial pollution in Japan, United Nations University Press, Japan.

5. Aoki, Tatsuya, Nagai, Mamoru (2010) The historical transition of rehabilitation and reforestation of degraded lands in Ashio Copper Mine: A consideration about the relationship among conservation, restoration and utilization of Matsugi district. Journal of Civil Engineering 66(2): 197-216.

6. Arahata K (1999) The extinction of Yanaka Village, Iwanami Shoten, Publishers, Tokyo, Japan.

7. Ooshika, Ishimune, (2009) The record of a wild person-the legend of Tanaka Shozo, Shinsensha Co Ltd, Tokyo, Japan.

8. Huang, Fu, Xue, Li (2018) A Century Long Ex-Post Evaluation of a Countermeasure for a Serious Pollution Problem in Japan. Sustainability 10(12): 4385

9. Kumamoto University (1966) Kumamoto University Medical School Minamata Disease Study Group, Minamata Disease: Study on the Organic Mercury Poisoning.

10. Harada, Masazumi (1972) Minamata Disease. Kumamoto Nichinichi Shinbun Centre \& Information Center/Iwanami Shoten Publishers.

11. Minamata Disease Municipal Museum (2007) Minamata Disease-Its History and Lessons.

12. Nakajima, Shigeki (2002) The progress of environmental restoration in Minamata Bay. Environmental Technology 31(11): 891-897. 